\title{
Cytogenetic analysis of Cycloramphus boraceiensis Heyer (Anura, Leptodactylidae)
}

\author{
Ana Paula Zampieri Silva ${ }^{1}$ \\ Célio F.B. Haddad ${ }^{2}$ \\ Sanae Kasahara ${ }^{1}$
}

\begin{abstract}
Cytogenetic analysis of Cycloramphus boraceiensis Heyer (Anura, Leptodactylidae). Cytogenetic studies on Cycloramphus boraceiensis Heyer, 1983 collected in Picinguaba, Ubatuba, State of São Paulo are presented. The species has $2 n=26$ karyotype formed by metacentrics, submetacentrics, and one telocentric pair which carries Ag-NORs. The C-banding patterns is also described.

KEY WORDS. Anura, Cycloramphus, chromosome, cytogenetics
\end{abstract}

The family Leptodactylidae, one of the most diversified groups of Anura, has been studied cytogenetically since the 50 's. However, the number of species and subspecies karyotyped until now, totalling about 200, is still reduced regarding to the more than 700 forms already described (KING 1990; KURAMOTO 1990). The subfamily Telmatobiinae, besides being the most abundant in representatives, presents the largest variability in chromosome number. In this subfamily, there is a predominance of two basic diploid number, $2 n=26$ and 22 , but karyotypes with $2 n=18,20,28,30,32$, and 36 were also found due to an exceptional chromosome variation in the genus Eleutherodactylus Duméril \& Bibron, 1841 (KING 1990; KURAMOTO 1990). Of the 25 species included in the genus Cycloramphus Ischudi, 1838 (FROST 1985; HEYER 1988; HADDAD \& SAZIMA 1989), only C. fuliginosus Tschudi, 1838 (BRUM-ZorRILla \& SAEZ 1968; BOGART 1970), C. asper Werner, 1899 (BEÇAK et al. 1970), and C. dubius Miranda-Ribeiro, 1920 (BEÇAK et al. 1970) have been karyotyped, all of them based exclusivelly on conventional staining technique.

For the first time, cytogenetic data on C. boraceiensis Heyer, 1983, including results on nucleolus organizer regions (Ag-NORs) and constitutive heterochromatin (C-band) are reported.

\section{MATERIAL AND METHODS}

Cytogenetic analysis in a sample of seven specimens of $C$. boraceiensis from

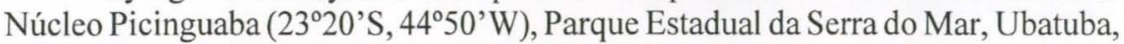
State of São Paulo: two males, four females, and one juvenile were performed. The voucher specimens were deposited in the amphibian collection of the Departamento de Zoologia, Instituto de Biociências, Universidade Estadual Paulista, Rio Claro, São Paulo, Brasil.

1) Departamento de Biologia, Instituto de Biociências, Universidade Estadual Paulista. Caixa Postal 199, 13506-900 Rio Claro, São Paulo, Brasil. E-mail: anapzs@rc.unesp.br

2) Departamento de Zoologia, Instituto de Biociências, Universidade Estadual Paulista, Caixa Postal 199, 13506-900 Rio Claro, São Paulo, Brasil. 
Chromosome spreads were obtained from direct cytological preparations of bone marrow, liver, and spleen as well as of testis in case of males, according to the procedures described in BALDISSERA et al. (1993). Conventional staining was performed with Giemsa diluted in phosphate buffer, $\mathrm{pH}$ 6.8. Ag-NOR staining was obtained by the technique of HOWELL \& BLACK (1980) and C-banding patterns, according to SUMNER (1972).

\section{RESULTS}

Cycloramphus boraceiensis has $2 \mathrm{n}=26$ karyotype formed by a large metacentric pair (Chromosome 1), four intermediate metacentric and submetacentric pairs (Chromosomes 2, 3, 4, and 5), one intermediate telocentric pair (Chromosome 6), and seven small metacentric and submetacentric pairs (Chromosomes 7 to 13). Pairs 1 to 6 can be easily identified according to their morphology and size. The unique telocentric is Chromosome 6 which presents a conspicuous secondary constriction in the proximal region of the long arms in both homologues (Fig. 1). No heteromorphic sex chromosome pair was recognized in male or female karyotype. Meiotic analysis revealed 13 bivalents in diplotene and metaphase I cells and 13 chromosomes in metaphase II cells (Fig. 2). The bivalents are in general ring shaped due to the presence of two terminal chiasmata. Open ring shaped bivalents due to the presence of one terminal chiasma were also observed.

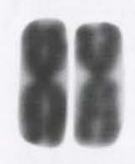

1

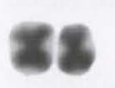

7

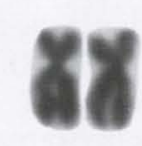

2

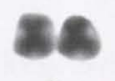

8

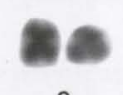

9

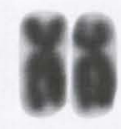

3

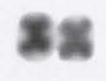

10

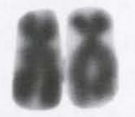

4

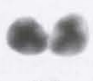

11

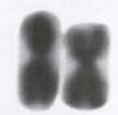

5

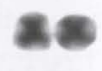

12

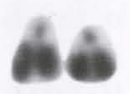

6

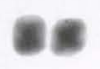

13

Fig. 1. Giemsa-stained karyotype of female specimen of $C$. boraceiensis with $2 n=26$. Note the secondary constriction in Chromosome 6.

Cycloramphus boraceiensis has a single pair of Ag-NORs which are located in the same site of the secondary constriction, in the long arms of the Chromosome 6 (Fig. 3). C-banding technique showed constitutive heterochromatin distributed in the centromeric region of the large and intermediate sized chromosomes (Fig. 4). The small Chromosomes 7 to 13 exhibited no C-positive staining. Besides the centromeric C-band, Chromosome 4 has a telomeric band in the short arms while Chromosome 2 has a slight interstitial band in the long arms and Chromosome 6, two bands heavily stained in the long arms (Fig. 4). 


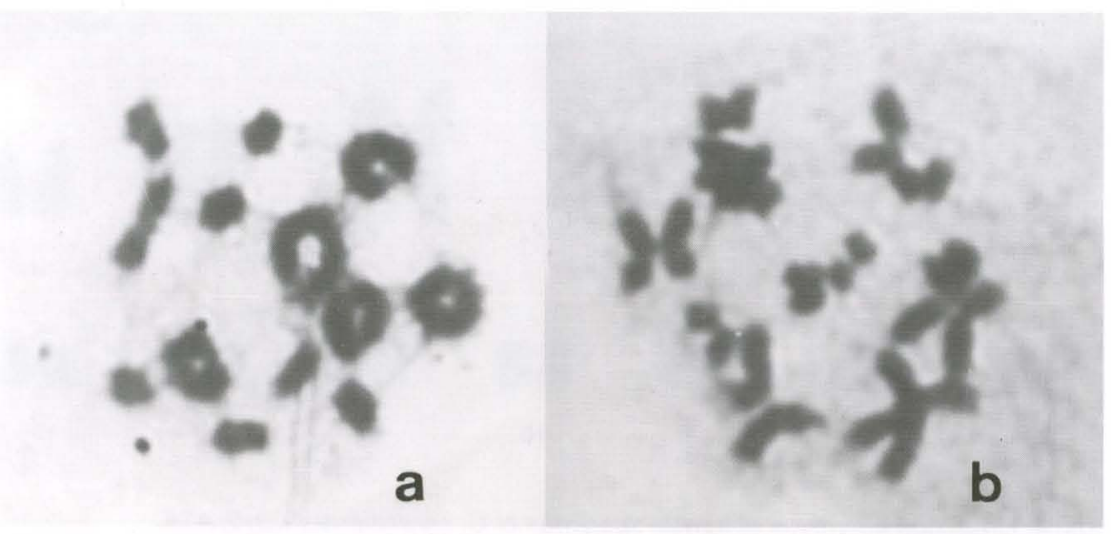

Fig. 2. Meiotic cells of $C$. boraceiensis with $2 n=26$. (A) Diplotene; (B) metaphase II.

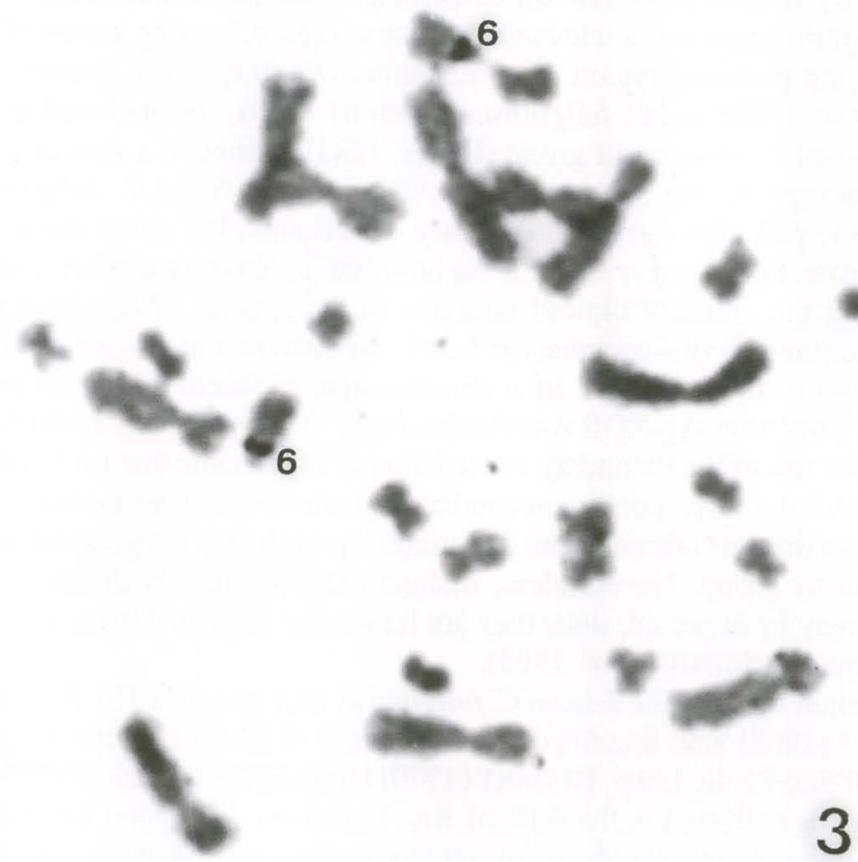

Fig. 3. Metaphase of C. boraceiensis showing Ag-NOR in Chromosome 6.

\section{DISCUSSION}

The species of the genus Cycloramphus have a geographical distribution restricted to the Brazilian Coastal Atlantic Forest (HEYER 1983). Cycloramphus boraceiensis is found in the Southeastern part of the state of Rio de Janeiro and the Northern half of the state of São Paulo, also including Ilha Grande and Ilha de São 


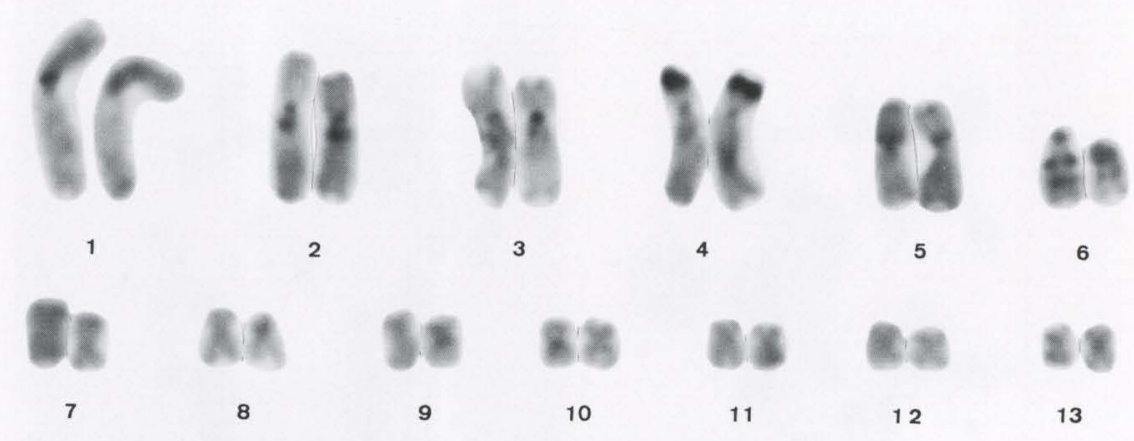

Fig. 4. C-banded karyotype of female specimen of $C$. boraceiensis with $2 n=26$.

Sebastião (FROST 1985). This species has the same karyotypic pattern described for C. dubius by BEÇAK et al. (1970), consisting by chromosomes of metacentric or submetacentric types and a telocentric Chromosome 6, bearing a secondary constriction in the proximal region. The remaining two karyotyped species, $C$. asper (BEÇAK et al. 1970) and C. fuliginosus (BOGART 1970), also included in the same morphological C. fuliginosus group (Heyer, 1983), exhibited a similar karyotypic formula, except by the submetacentric Chromosome 6. In C. fuliginosus, this chromosome pair also carries a secondary constriction, but at the distal region of the long arms. For $C$. asper, there is no information about secondary constriction. Considering the constant diploid numbers in the species of Cycloramphus, the distinct morphology of Chromosome 6 in C. boraceiensis and C. fuliginosus could be attributed to the ocurrence of a chromosomal repatterning due to pericentric inversion. Until now, Ag-NOR was obtained only in C. boraceiensis, whose location match to the site of the secondary constriction. It is probable that for C. dubius and C. fuliginosus the corresponding secondary constrictions in Chromosome 6 are also Ag-NOR, so that this chromosome pair might represent a cytological marker for the C. fuliginosus group. Nevertheless, distinct chromosome localization of rDNA segments may be expected, since they are frequently subjected to minute structural rearrangements (SCHMID et al. 1995).

Former cytogenetic data on C. fuliginosus were presented by BRUM-ZORRILLA \& SAEZ (1968) who described diploid number of 22 for specimens collected in the state of São Paulo. Later, BOGART (1970) reported the typical $2 n=26$ karyotype for specimens collected in the state of Rio de Janeiro. Excepting these discrepant data, the remaining species of Cycloramphus have a very similar karyotypic pattern, so that other chromosome differentiation techniques might be used in cytogenetic studies of this genus. One of this approach is the C-banding, which was useful to discriminate very close taxonomically distinct forms, as reported by ANDERSON (1991) for $2 \mathrm{n}=24$ holarctic species of the genus Hyla and by MATSUI et al. (1985) for $2 \mathrm{n}=22$ representatives of the Bufo bufo complex. Unhappily, C-band tecnique was applied until now only in the chromosomes of $C$. boraceiensis. It would be interesting to know if its characteristic C-banding pattern is species-specific or may be extended to the other species of the $C$. fuliginosus group. 
The subfamily Telmatobiinae is considered along with Ceratophryinae and Hylodinae, the most ancestral in the family Leptodactylidae (KING 1990). According to this author, the majority of the species included in these subfamilies exhibit $2 n=26$ karyotype, formed by metacentric and submetacentric chromosomes. The representatives of the subfamily Leptodactylinae, considered the most derived in the family Leptodactylidae, have predominantly $2 n=22$ karyotype. The reduction of the chromosome number from 26 to 22 is probably due to centric fusion, considered by MORESCALCHI (1973), the major event in the karyotypic evolution in amphibians.

ACKNOWLEDGMENTS. To CNPq and FAPESP for finantial support. Instituto Florestal de São Paulo for logistic support.

\section{REFERENCES}

Anderson, K. 1991. Amphibian Cytogenetics and Evolution, p. 299-328. In: D.M. GreEn \& S.K. SESsions (Eds). Chromosome evolution in Holaretic Hyla treefrogs. San Diego, Academic Press, 456p.

Baldissera JR., F.A.; P.S.L. Oliveira \& S. Kasahara. 1993. Cytogenetics of four Brazilian Hyla species (Amphibia-Anura) and description of a case with a supernumerary chromosome. Rev. Brasil. Genet. 16: 335-345.

BEÇAK, M.L.; L. DENARO \& W. BEÇAK. 1970. Polyploidy and mechanisms of karyotypic diversification in Amphibia. Cytogenetics 9: 225-238.

BoGART, J.P. 1970. Systematic problems in the amphibian family Leptodactylidae (Anura) as indicated by karyotypic analysis. Cytogenetics 9: 369-383.

Brum-Zorrilla, N. \& F.A. Saez. 1968. Chromosomes of Leptodactylidae (Amphibia anura). Experientia 15 (9): 969.

Frost, D.R. 1985. Amphibian Species of the World. Lawrence, Allen Press, Inc and The Association of Systematics Collection, 732p.

HadDad, C.F.B. \& I. Sazima. 1989. A new species of Cycloramphus from Southeastern Brazil (Amphibia, Leptodactylidae). Herpetologica 45 (4): 425-429.

HEYER, W.R. 1983. Variation and systematics of frogs of the genus Cycloramphus (Amphibia, Leptodactylidae). Arq. Zool., São Paulo, 30: 235-339.

- 1988. A notable collection of Cycloramphus (Amphibia, Leptodactylidae) from Bahia, Brazil, with a description of a new species (Cycloramphus-Migueli). Proc. Biol. Soc. Wash. 101 (1): 151-154.

HOWELL, W. \& D.A. BLACK. 1980. Controlled silver-staining of nucleolus organizer regions with a protective colloidal developer: a 1-step method. Experientia 36: 1014-1015.

KING, M. 1990. Animal Cytogenetics. Amphibia, 4. Chordata 2. Berlin, John B., 241p.

Kuramoto, M. 1990. A list of chromosome numbers of anuran amphibians. Bull. Fukuoka Univ. Educ. 39: 83-127.

MATSUi, M.; T. SETO; Y. KohSAKA \& L.J. Borkin. 1985. Bearing of chromosome C-banding patterns on the classification of Eurasian toads of the Bufo bufo complex. Amphibia-Reptilia 6: 23-33.

Morescalchi, A. 1973. Amphibia, p. 233-248. In: A.B. Chiarelli \& E. CapanNa (Eds). Cytotaxonomy and Vertebrate Evolution. London, Academic Press, 783p.

SChmid, M.; W. Feichtinger; R. Weimer; C. Mais; F. Bolaños \& P. León. 1995. Chromosome banding in Amphibia. XXI. Inversion polymorphism and multiple nucleolous organizer regions in Agalychnis callidryas (Anura, Hylidae). Cytogenet. Cell Genet. 69: 18-26.

SumNer, A.T. 1972. A simple technique for demonstrating centromeric heterochromatin. Exptl. Cell Res. 75: 304-306.

Recebido em 02.III.2000; aceito em 29.III.2001. 